The grasp shown by Cavendish of the complex nature of wear was masterly; it could have been studied with advantage by investigators a century later.

\section{Conclusions of the Final Report}

Thus it was reported back to the Committee of the Privy Council that there was nothing to be gained by substituting a harder or a softer coinage alloy for the standard 22 carat gold, though Hatchett did not say it in so many words. His conclusions are too verbose for full quotation, but an extract will give their substance.

"The extraordinary loss," he wrote "which gold coin of this kingdom is stated to have sustained within a certain limited time cannot, with even a shadow of probability, be attributed to an important defect in the composition or quality of the standard gold: and all that can be said upon the subject is, that some portion of this loss may have been caused by the rough impression and milled edge now in use, by which each piece of coin acts, and is acted upon by others, in the manner of a file. ... When a number of guineas, rather loosely packed, have been long shaken together by the motion of a coach or other carriage, the effects of friction are observed chiefly to fall upon only a few of the pieces. ... Upon the whole there is every reason to believe that our gold coin suffers little by friction upon itself and the chief cause of natural and fair wear arises from particles to which they are exposed in course of circulation."

What the Committee thought is not recorded, but in May 1816, in the briefest of reports, they recommended to the Privy Council that there should be no change in the standard weight or denomination of the gold coin of the realm. Further-and they needed here no research effort to guide them-they proposed that in making silver coins the Master of the Mint should make 66 shillings instead of 62 from each troy ounce of standard silver and return 4 shillings as Brassage or Seignorage to pay for a New Mint!

Hatchett and Cavendish were not able to find a means of reducing the wear of gold coins, but the distinguished Committee was nevertheless able to propose a statesmanlike means of compensating for the inevitable losses ... simply by debasing the silver coinage.

\title{
What Things may be gilded and laid on with Silver or Gold, and what not
}

$I^{\mathrm{T}}$ TEM, Whereas many fraudulent Artificers, imagining to deceive the common People, do daily make Locks, Rings, Beads, Candlesticks, Harness for Girdles, Hilts, Chalices, and Sword-pomels, Powder-boxes, and Covers for Cups, of Copper and of Latten, and the same overgilt and silver like to Gold or Silver, and the same sell and put in Gage to many Men, not having full Knowledge thereof, for whole Gold and whole Silver, to the great Deceit, Loss and Hindrance of the common People, and the Wasting of Gold and Silver; (2) it is ordained and established, That no Artificer, nor other Man whatsoever he be, from henceforth shall gilt nor silver any such Locks, Rings, Beads, Candlesticks, Harness for Girdles, Chalices, Hilts, nor Pomels of Swords, Powder-boxes, nor Covers for Cups, made of Copper or Latten, upon Pain to forfeit to the Kings Cs. at every time that he shall be found guilty, and to make Satisfaction to the Party grieved for his Damages; (3) but that (Chalices always excepted) the said Artificers may work, or cause to be wrought, Ornaments for the Church of Copper and Latten, and the same gilt or silver, so that always in the Foot, or in some other Part of every such Ornament so to be made, the Copper and the Latten shall be plain, to the Intent that a Man may see whereof the Thing is made, for to eschew the Deceit aforesaid.

An Act of Parliament passed in the Year $\mathrm{I}_{4} \mathrm{O} 3$ in the Reign of King Henry IV 